\title{
Relectura de Los Empeños de una casa*
}

Irving A. Leonard en su ya clásico libro La época barroca en el México colonial, señaló la "cualidad enigmática de los versos" de Sor Juana Inés de la Cruz a través de los cuales se "perciben los destellos de un refinado espỉritu en profundo conflicto consigo mismos, de un personaje ambivalente... desgarrado por dualismos antagónicos."1 Estas cualidades tan certeramente identificadas por Leonard, están también presentes en su comedia de capa y espada Los empeños de una casa (ca. 1684). Alli se entrelazan temáticamente el amor y el honor mientras que motivos subyacentes se vinculan a esquemas barrocos y al dilema intelectual que atenazó a la autora a lo largo de su vida. El examen cuidadoso de Los empeños revela cuan ligada está la biografỉa de la monja mexicana a sus escritos, y a su vez manifiesta los estrechos vinculos de texto y contex to en las letras virreinales. No es necesario recalcar aquí su vida, su doloroso conflicto entre su voluntad de saber y las imposiciones eclesiásticas, ni las limitaciones impuestas a la mujer por la sociedad colonial. Es fácil imaginar el conflicto interior que debieron producir todas estas limitaciones en la extremadamente inteligente y bella mujer que fue Sor Juana. La discrepancia entre lo que la sociedad quería que fuera y lo que ella deseaba ser signó angustiosamente su vida y sus escritos.

Sabemos que tanto el engaño sensorial como la limitación del intelecto fueron constantes preocupaciones de Sor Juana. En su Respuesta a Sor Filotea (1690), ensayo racionalista y documento de avanzada feminista a veces descuidado por la crítica actual, la monja lamenta que sus sentidos la traicionan cuando ve que las lineas para-

*Una versión abreviada de este trabajo fue leĩda en la sesión sobre literatura colonial en honor de Irving A. Leonard en el XVIII Congreso del Instituto Internacional de Literatura Iberoamericana, University of Florida, Gainesville, 27 de marzo al 9 de abril de 1977. 
lelas se acercan y se unen en aparente violación física y mental. ${ }^{2}$ Desde el comienzo de Los empeños, el tema del amor se relaciona con los sentidos y sus engaños. El amor es "ciego"3 y los obcecados por él terminan ignorando al mundo circundante en búsqueda del logro de sus propósitos (II, 178). Por eso no extraña que Pedro se finja otro para rescatar a Leonor de don Carlos, ni asombra que éste huya al creerse perseguido por la justicia. La sirvienta Celia anticipa los futuros disfraces de la realidad:

Señora, nada me admira
que en amor no es novedad
que se vista la verdad
del color de la mentira. ( $I, 97)$

No sorprende tampoco que la primera jornada termine con los protagonistas reunidos en la misma casa, pero incomunicados física y espiritualmente por el enredo causado por acciones desatadas por la pasión. Carlos, Leonor, Ana y Juan se hallan en una habitación oscura y sólo la criada Celia, que lleva una luz, conoce la verdad, clave del enredo. La luz física ilumina la habitación, pero los protagonistas, cegados por su pasión, no se reconocen y la luz de la vela los sume en mayor oscuridad mental.4 Leonor, guiada por lo que ve, cree que Carlos es amante de Ana; y don Juan, dirigido por sus sentidos y celos, se equivoca dos veces: le habla a Leonor creyendo que es Ana y concluye, al verla junto a Carlos, que los dos son amantes (I, 128). Carlos; por su parte, no se deja llevar ni por los sentidos ni por los celos. A pesar de haber visto juntos a Leonor y a don Juan y haber escuchado los requiebros de éste, nunca culpa a Leonor. La contención de don Carlos tipifica a la persona que vive racionalmente, suprime el juicio apresurado y desea, con mayores pruebas, llegar a una conclusión lógicamente inalterable. Pero en su afán de "discurrirlo todo", Carlos, en realidad, no acierta a "discurrir nada" (I, 130). Valiéndose de esta antítesis la monja mexicana parece reconocer la imposibilidad del intelecto para llegar a saberlo todo; y advierte también el peligro a que nos puede conducir el querer aprehender el mundo de manera absoluta.

El juego ilusión-realidad continúa en la segunda jornada, cuando don Carlos le confiesa a su criado Castaño haber visto a Leonor (II, 138). La respuesta de Castaño evidencia la traición sensorial:

Aquesto será, Señor que quien bueyes ha perdido 
como has perdido a Leonor

se te aparecen Leonores (II, 138)

Y cree que su amo ha perdido la razón por completo:

¿A Leonor? ¿Hazlo soñado?

¡Hay tan grande boberỉa!

Yo por loco te tenía,

pero no tan declarado. (II, 141)

Para acentuar el juego de polaridades (realidad / ilusión: cordura / locura; tener / carecer; razón / pasión; luz / oscuridad; ser / no ser) Celia describe a Leonor como "fantasma" (II, 131). Por la misma razón Leonor se pregunta si el lugar donde está escondida es "casa" o "encanto" (I, 189); y Carlos interroga: "Es ilusión, es encanto / lo que ha pasado por mí? / ¿Quién soy yo? / ¿Dónde me hallo?" (II, 167). Subrayan el ambiente de incomunicación, de alteración, de desorden social y espiritual las puertas cerradas (II, 155; III, 197), las luces que se apagan (III, 215) y encienden (II, 218), el manto que oculta las caras (III, 238), el constante desplazamiento de los personajes de una habitación a otra. Quizá el ejemplo más patente de esa incomunicación y caos lo ofrece don Rodrigo:

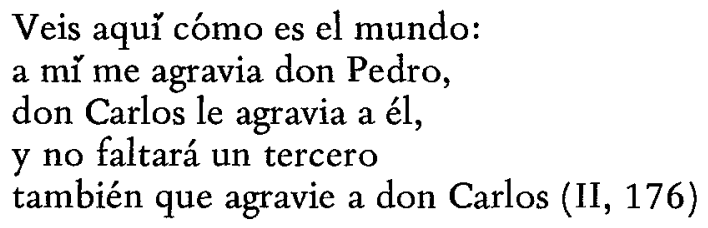

Sus conclusiones son del todo erradas: ni a él lo afrenta don Pedro, ni don Carlos ofende a don Pedro. Sin embargo, in triga la conclusión de don Rodrigo:

\author{
$\mathrm{Y}$ es que lo permite el cielo \\ en castigo de las culpas \\ y dispone que paguemos \\ con males que recibimos \\ los males que habemos hechos. (II, 176)
}

Sor Juana atribuye aquil los sufrimientos experimentados por el hombre a "castigos" divinos por los "males" que ha hechorecuérdese su repetida frase: "Soy mi propio verdugo." ¿No están impregnadas estas lǐneas de una resignación que augura la futura renuncia de la monja a la pesquisa intelectual? ¿No expresan ellas su incomprendido deseo de reconciliar lo divino y lo racional? 5 
También doña Ana se vale de "industria engañosa" (II, 152): para que la "pasión celosa" se apodere de don Carlos, lo invita a que se acerque a la reja y oiga la música; ahí verá a Leonor y a don Pedro juntos, pero no escuchará su conversación. El suave canto que oyen los protagonistas se troca en la imagen auditiva de su violento sentir. La alternación de "sí es tal / no es tal" (II, 158-164), primero del coro y después de los amantes, destaca el tema central de la obra, a la vez que sugiere las múltiples y esquivas facetas de una realidad diferente para cada enamorado. $6 \mathrm{Si}$ la mayor pena para don Pedro es "carecer del favor" de la amada (II, 160), para su hermana son los celos (II, 161). Leonor opina que el sufrimiento peor es "el carecer de lo amado / en amor correspondido" (II, 161). Carlos no se atreve a celar a su amada. Sólo el temor a experimentar esta desconfianza es para él "sobrado mal" (II, 162). A su vez, la conversación entre los criados ridiculiza las penas de amor y las reduce a ambiciones puramente materiales: Castaño no tiene dinero para obsequiar a la amada y Celia se queja de sus muchos enamorados porque no expresan sus sentimientos en dádivas (II, 162-163). El lector cuidadoso de esta escena nota que tanto criados como amos-con la excepción de Carlos-ven al mundo con el deformado lente de sus ambiciones y pasiones egoistas; los sentidos, "cegados" e impedidos por ellas, también producen una imagen distorsionada del mundo empírico. ${ }^{7}$ Asǐ mismo la escena indica cuan importantes para el desarrollo de tema y trama son los personajes secundarios: ellos actúan como cîrculos concéntricos que reflejan y amplian el centro de la acción, subrayan temas y subtemas y hasta ocasionalmente desplazan a los protagonistas: 8

Entre los personajes principales, sólo Carlos reconoce el peligro de una pasión malguiada, y sólo él rechaza briosamente los celos (II, 112). Reafirmando su confianza en Leonor, exclama:

No hasta saber cómo vino, que si yo en la casa propia estoy, sin estar culpado ¿cómo quieres que suponga culpa en Leonor? Antes juzgo que la fortuna piadosa la condujo adonde estoy. (II, 156)

$\mathrm{Y}$ ante las impertinencias de su criado, agrega:

Calla, Castaño, la boca, que es muy bajo quien sin causa de la dama a quien adora, 
se da a entender que le ofende, pues en su aprensión celosa ¿qué mucho que ella le agravie cuando él a sí se deshonra? (II, 157)

Estos versos no son exclusivamente una protesta amorosa, o reafirmación del ejercicio de la razón vis a vis la pasión. Don Carlos se comporta en forma muy diferente a otros galanes deseosos de venganza, empujados por la sospecha de una traición femenina. Al no condenar a Leonor, Carlos la eleva a su nivel y asume la igualdad del hombre y de la mujer: si él no ha traicionado a Leonor ¿por qué debe pensar que Leonor lo traiciona? Sutilmente, Sor Juana se revela aquí contra la imagen arquetípica de la liviandad femenina y el código de honor expuestos en la literatura de entonces y reclama los derechos de la mujer a ser tratada y juzgada, no por las apariencias, sino por la razón y la verdad. Además, condena al hombre que actúa guiado únicamente por sus sospechas: "él a sǐ se deshonra."

La supuesta ligereza femenina es tratada otra vez cuando don Rodrĭgo, el padre de Leonor, lamenta la escapada de su hija:

¡Oh fiera! ¿Quién dirìa

de aquella mesurada hipocresia

de aquel punto y recato que mostraba,

que liviandad tan grande se encerraba

en su pecho alevoso?

¡Oh mujeres! ¡Oh monstruo venenoso!

$¿$ Quién en vosotros fìa

si con igual locura y osadía,

con la misma medida

se pierde la ignorante y la entendida? (II, 119)

Pero en Los empeños las mujeres se aprovechan de esta falta tradicionalmente adjudicada a ellas. La Décima Musa recalca que esta falla atañe a hombres y mujeres por igual. Precisamente por esto Ana nunca pierde la esperanza de conquistar a don Carlos pues:

¿qué voluntad hay tan fina

en los hombres, que si ven

que otra ocasión los convida

la dejen por la que quieren? (I, 115)

Por su condición de mujer inteligente y hermosa, Sor Juana habia sido discriminada. Ya sabemos que la inferioridad de las mujeres en el México del siglo XVII era lamentablemente axiomática. Ellas eran juguetes de padres, hermanos y esposos; y su "curiosidad intelectual 
era indecorosa y aun pecaminosa."9 Estos prejuicios sociales se manifiestan cuando Ana comenta:

\author{
Leonor, tu ingenio y cara \\ el uno a otro se malogra, \\ que quien es tan entendida \\ es lástima que sea hermosa (II, 147)
}

Los versos resumen el punto de vista imperante que Sor Juana desafía cuando en esta obra reconcilia la independencia, la hermosura y la inteligencia femeninas en Leonor y Ana.

Es importante destacar el concepto del honor desarrollado por Sor Juana en Los empeños. El honor sigue siendo "un cristal tan terso / que, si no le quiebra el golpe, / le empaña sólo el aliento" (III, 227); y sus males "se han de curar con diligencia, / porque el que lo dilata neciamente / viene a quedarse enfermo eternamente" (III, 221). Por otra parte, las acciones de don Rodrigo apuntan un cambio. El padre está ansioso de vengar su afrenta, pero cuando su criado Hernando le explica las ventajas de un enlace entre el presunto burlador don Pedro y doña Leonor, don Rodrigo quiere convertir a su ofensor "de enemigo en hijo" (I, 121). El viejo caballero ejemplifica una actitud más razonada en los lances de honor, y la urgencia de contener las pasiones para evitar la tragedia (III, 224-227). Sor Juana, como su maestro Calderón, critica asǐ el hueco código de honor basado únicamente en las apariencias.

Además de la nota autobiográfica ya destacada y señalada en forma más amplia por José Juan Arrom en su certero análisis de Los empeños de una casa, 10 encontramos en esta comedia otro ejemplo de "correspondencias encontradas": don Juan ama a Ana; Ana ama a Carlos-“Que es Carlos mál galán, y aunque no fuera, / tiene de más galán el ser ajeno" (I, 114); don Carlos ama a Leonor; y don Pedro adora a Leonor. Estas correspondencias en la obra poética de la monja mexicana fueron estudiados por Irving A. Leonard en un temprano trabajo suyo. ${ }^{11} \mathrm{La}$ constante reaparición de estas antítesis triangulares indica, como bien apuntó Leonard, un profundo conflicto interior que puede resumirse asǐ: la Iglesia ama a Sor Juana y desea que ella siga los pasos escolásticos: Sor Juana ama al mundo secular y empírico; éste, a su vez, "parecía desdeñarla e, inevitablemente, el de Sor Juana fue un amor marchito-el rechazo por parte del amado y el estar poseida por el no amado-una antítesis triangular."12

Que el engaño de los sentidos es tema subyacente y a la vez clave en el desarrollo de la trama y del tema es evidente en toda la 
comedia; recordemos, por ejemplo, el comentario de Ana: "Aunque si eres tan hermosa, / no es mucho ser desdichada" (I, 103). Ana guiada por lo aparente, no se da cuenta que la belleza nunca compensa la infelicidad. Este motivo se intensifica en la tercera jornada cuando don Pedro es burlado por Castaño. El embeleco del criado está subrayado por alusiones al querer ser: Leonor quiso ser Elena de un Paris boquirrubio (III, 202); Castaño quiere ser Leonor, y, como Jacobo cuando engañó a su padre, ahora se cubre las manos con guantes y se tapa la cara con el manto para engañar al mundo. El criado está consciente de que lo seguirán:

cuatro mil lindos
de aquestos que galantean
a salga lo que saliere,
y que a bulto se amartelan,
no de la belleza que es
sino de la que ellos piensan? (III, 205)

Ni Leonor es Elena de Troya, ni Castaño es Leonor. Ambos se olvidan momentáneamente de lo que son: se olvidan de su realidad. En la fingida Leonor encontramos el reflejo de la verdadera Leonor, aunque vista en el espejo barroco de la deformidad; es la suya una imagen caricaturesca, inversión de la real. La imagen deforme de Leonor acepta los convencionalismos sociales cuando da su palabra de matrimonio a don Pedro. Se refleja aquí precisamente lo elidido-el alterado orden social que exige el conformismo. La jocosa escena contrasta también con otras comedias del Siglo de Oro en que la mujer. se viste de hombre para lograr sus propósitos. A través del disfraz de Castaño, Sor Juana se mofa del sexo opuesto y de una sociedad, que, como la masculina, se guia por las apariencias. ${ }^{13} \mathrm{La}$ monja mexicana intuye también que ni los sentidos ni la razón conducen al conocimiento absoluto, a la perfección; ambos nos están vedados. Es su búsqueda la que importa y eleva como sucede en el Primero Sueño. 14

Pedro también se olvida de quién es. Manejado por su pasión realiza acciones indignas y se deja llevar por lo aparente-la belleza que "piensa" encubre el manto (III, 205). Sucumbe fácilmente al engaño de la fingida Leonor, aunque reconoce sus disparates pronunciados con voz atiplada, como extraños al ingenio y carácter de la dama (III, 208). Ciego de amor y seducido por lo que imagina, concluye arrogantemente que Leonor "se finge necia por ver" si asi lo despecha (III, 209). Termina encerrando a la falsa Leonor "por de 
fuera, / porque si acaso lo finge / se haga la burla ella mesma" (III, 219). Pedro resulta ser el necio y como tal no se da cuenta que sólo controla lo exterior, lo aparente, lo que cree verídico, y no la realidad espiritual de su amada. ${ }^{15}$ El encierro y el disfraz son una doble burla a la masculinidad y autoridad de don Pedro, resquebrajada ya por sus acciones y las de su hermana. Alucinado, lo engaña la caricatura de Leonor-un criado disfrazado de mujer; candados y cerrojos no han impedido que doña Ana realice sus propósitos. El atrevido galán ha sido embaucado por su hermana (realidad) y por la Leonor que "piensa" (ilusión). El burlador, al fin, es burlado.

La vela que ha apagado Castaño en la tercera jornada es indicativa de la confusión espiritual que rige a los amantes, de una realidad que disfrazan los sentidos y la razón mal guiados por la pasión. La partida de Carlos y Leonor (a quien el galán cree Ana) y de Juan y Ana (a quien la joven cree Carlos) apunta momentáneamente hacia la restauración del orden. Pero éste no imperará hasta que todos se quiten mantos y disfraces, y Carlos y Leonor expongan abiertamente sus sentimientos.

Al final de la tercera jornada, la confusión de don Pedro es abrumadora: "¿Qué es esto? ¿Por dicha sueño? / Leonor está aquí y allï" (III, 245). Cae ahora el doble opaco del desciframiento. ${ }^{16} \mathrm{El}$ engaño suscitado por don Pedro al comienzo de la comedia tiene trágicas consecuencias. El mismo pierde a su amada y nunca aprende la lección pues continúa con el juego de las apariencias (III, 247). Ana, vǐctima del engaño propiciado por ella, termina aceptando a don Juan: empero, como su hermano, sigue con los fingimientos (III, 243). Sólo don Carlos obra generosa y abiertamente. No vacila en sacrificar sus ambiciones amorosas para salvar el honor de Ana (II, 173), y cuando la cree fuera de peligro, actúa limpiamente porque "No hay por qué esconder la cara" (III, 236). La comedia llega a su terminus con la clásica restauración del orden social en los matrimonios de Leonor y Carlos, Juan y Ana y el castigo de Pedro. Con todo, su núcleo se escinde: felicidad y amor (Carlos y Leonor); amor, desamor y apariencia (Juan y Ana); soledad y fingimiento (don Pedro), son tres alternativas posibles. Cirrculos que parecen cerrarse al escoger, pero que se continúan infinitamente: ellos revelan la pérdida del centro dictado por la estética clásica y el surgimiento de las órbitas concéntricas que subrayan la concepción barroca del arte y de la vida. 17

En la biografía de la monja, las opciones representadas en la comedia señalan las irreconciliables alternativas-círculos siempre 
elusivos-impuestos por una sociedad y un orden petrificados que obligan a Sor Juana a una negación última: su renuncia a la aventura del intelecto. La sumisión de Ana a Juan y la fingida felicidad de ella bien pueden aludir a los días en que Sor Juana vivió en la corte virreinal sometida también a sus caprichos y a los de su protectora la condesa de Mancera. ${ }^{18}$ Es posible enlazar también la soledad de Pedro con la de Sor Juana. Los dos han buscado la felicidad por diversos caminos. Uno lo ha hecho urdiendo mentiras para lograr el amor de su amada; la otra, usa la razón para saciar su sed de conocimiento. Ambos fracasan en sus afanes, vǐctimas de una realidad muy diferente a la que deseaban forjar: Leonor nunca podrá amar a don Pedro por estar enamorada de don Carlos; el mundo colonial no le permitirá a Sor Juana satisfacer su sed intelectual ni en la corte ni en el convento. Si reconocemos que en esa época "tener fe en Dios y en la razón a un mismo tiempo es vivir con el ser arraigado, desgarrado si se prefiere, en la posibilidad real, única, extremosa y contradictoria, constituída por dos posibles imposibles del existir humano," entenderemos mejor el conflicto que consumió a esta monja jerónima en su intento de reconciliar la razón y la fe, el descentramiento de su vida ahogada en la marejada escolástica. Sor Juana buscó e intuyó la esquividad del mundo ideal presentado en Los empeños de una casa por la unión final de Leonor y Carlos. Paradójicamente, su búsqueda constante le costará el silencio como escritora y la vida.

La aparentemente jocosa y limpida comedia de nuestra Décima Musa es signo de su vida y de su época: claroscuros, altibajos, duplicidad, contradicciones. En Los empeños de una casa y en todos los escritos de Sor Juana advertimos "la melancolía de un espíritu que no logró nunca hacerse perdonar su atrevimiento y su condición de mujer." 19 En su obra buscamos el significado de una vida que se nos escapa. Como bien ha dicho Leonard, buscamos la cifra "en el destello del relámpago."20

The City College, CUNY

RAQUEL CHANG-RODRIGUEZ

\section{NOTAS}

1. Baroque Times in Old Mexico (Ann Arbor: The University of Michigan Press, 1959). Citamos por la traducción de Agustǐn Escurdia, La época barroca en el México colonial (México: Fondo de Cultura Económica, 1974), p. 255.

2. Georgina Sabat de Rivers, "Sor Juana y su Sueño: antecedentes científicos en la poesia española del Siglo de Oro," Cuadernos Hispano- 
americanos, No. 310 (1976), p. 197. V. también Alfredo A. Roggiano, "Conocer y saber en Sor Juana Inés de la Cruz," Revista de Occidente, No. 15, 3ra época (1977), pp. 51-54.

3. Los empeños de una casa en Poesía, teatro y prosa de Sor Juana Inés de la Cruz, 2da ed. (México: Porrúa, 1965), I, 95. Citamos por esta edición indicando la jornada y página correspondientes en el texto. Para una buena discusión de El amor es más laberinto, la otra comedia escrita por Sor Juana, v. Margaret Sayers Peden, "Sor Juana Inés de la Cruz: The Fourth Labyrinth," Bulletin of Comediantes, 27 (1977), 41-47.

4. V. Vern G. Williamsem, "La simetria bilateral de las comedias de Sor Juana Inés," ponencia presentada en el XVII Congreso del Instituto Internacional de Literatura Iberoamericana, Universidad Complutense, Madrid, marzo de 1975.

5. Octavio Paz ha señalado que para Sor Juana "todo viene de Dios;" ella "siempre busca una explicación racional," El laberinto de la soledad (México: Cuadernos Americanos, 1950), p. 115.

6. La importancia de la música y la pintura en el teatro del Siglo de Oro ha sido poco estudiada. En muchas obras ( $E l$ mayor monstruo del mundo; $E l$ pintor de su deshonra) las dos artes desempeñan un papel primordial en el desarrollo del tema.

7. El profesor Leonard me ha sugerido que probablemente este personaje perfecto ha sido llamado Carlos en deferencia al sabio polígrafo mexicano Carlos de Sigüenza y Góngora con quien Sor Juana compartió inquietudes intelectuales y una profunda amistad. Recordemos que la monja, en el soneto que le dedicó a su amigo, lo llama "Dulce, canoro cisne mexicano / cuya voz si el Estigio lago oyera, segunda vez a Eurídice te diera / y segunda el Delfĭn te fuera humano" p. 58.

8. En su ya citada ponencia, Vern G. Williamsen destaca cómo los personajes secundarios en El amor es más laberinto "reflejan y realizan" el tema principal. Williamsen agrega correctamente que este es un aspecto de la estructura de la comedia que merece estudiarse detalladamente.

9. Leonard, p. 261.

10. Historia del teatro hispanoamericano: época colonial, $2 \mathrm{da}$ ed. (México: de Andrea, 1967), pp. 83-87.

11. "The 'encontradas correspondencias' of Sor Juana Inés de la Cruz: An Interpretation," Hispanic Review, 23 (1955), 33-47. Una versión abreviada apareció en Lewis Hanke, ed. History of Latin American Civilization (Boston: Little, Brown \& Co., 1967), I, 377-387. V. también Joseph A. Feustle Jr., "Hacia una interpretación de Los empeños de una casa de Sor Inés de la Cruz," Explicación de Textos, 1 (1972), 146.

12. Leonard, La época barroca . . ., p. 273.

13. Sobre esta transformación de Castaño, V. Elías J. Rivers, "Indecencias de una monjita mejicana," Homenaje al Profesor William L. Fitcher, eds. José Amor y Vázquez y A. David Kossoff (Madrid: Castalia, 1971), pp. 633-637. 
14. Sabat de Rivers, p. 198.

15. Sor Juana nos narra una experiencia paralela en la Respuesta a Sor Filotea, p. 275: "Una vez lo consiguieron con una prelada muy santa y muy cándida que creyó que el estudio era cosa de Inquisición y me mandó que no estudiase. Yo la obedecí (unos tres meses, que duró el poder ella mandar) en cuanto a no tomar libro, que en cuanto a no estudiar absolutamente, como no cae debajo de mi potestad no lo pude hacer, porque aunque no estudiaba en los libros, estudiaba en todas las cosas que Dios crió, sirviéndome ellas de letras, y de libro toda esta máquina universal." Es imposible controlar la realidad espiritual de cada uno.

16. Severo Sarduy, Barroco (Buenos Aires: Editorial Sudamericana, 1974), p. 81.

17. Sarduy, pp. 55-71.

18. Jaime Concha, "La Literatura Colonial Hispanoamericana: problemas e hipótesis," Neohelicon (Budapest), 4, Nos. 1-2 (1976), 42.

19. Paz, p. 118.

20. Leonard, p. 255. 
